\title{
Jóvenes, cultura escolar y comunicación
}

Jeunes, culture scolaire et communication

Jovens, cultura escolar e comunicação

Fecha de recepción: 6 DE MAYO DE 2014 / Fecha de aceptación: 10 DE NOVIEMBRE DE 2014 / Fecha de disponibilidad en línea: 15 DE MARZO DE 2015

Encuentre este artículo en http://magisinvestigacioneducacion.javeriana.edu.co/

doi: 10.11144/Javeriana.M7-15.JCEC

Escrito por Flor Ángela Gutiérrez-Castro Universidad Distrital Francisco José de Caldas BOGOTÁ, COLOMBIA anguca_80@hotmail.com

\begin{abstract}
Resumen
En este artículo de revisión se estudian las investigaciones que en las últimas dos décadas han reflexionado sobre los jóvenes en la cultura escolar, desde los campos sociocultural, socioeducativo y sociodiscursivo. Dichos estudios permitieron un primer acercamiento a las nociones de jóvenes, cultura escolar-universo cultural juvenil, comunicación y subjetividad. Aunque los campos se abordan esquemáticamente, se profundiza en la reflexión sociodiscursiva para comprender tanto las interacciones sociales de los jóvenes en el plano comunicativo y su relación con la forma en que estos sujetos configuran su forma de ser y estar en la escuela, como la manera en que esta institución ha afectado las subjetividades que allí se construyen.
\end{abstract}

\section{Palabras clave descriptor}

Joven, escuela, cultura y comunicación.

\section{Transferencia a la práctica}

Las implicaciones de este proyecto investigativo en las prácticas pedagógicas tienen que ver con la búsqueda y construcción de una propuesta metodológica y conceptual que permita, por medio de escenarios comunicativos/cultura de la imagen, canalizar procesos de configuraciones subjetivas diversas en los jóvenes de la cultura escolar. Es una propuesta que, además de generar cambios metodológicos y prácticos, busca que los jóvenes, sobre la base de producciones simbólicas, configuren sus formas de ser y estar en la escuela, y se reconozcan a sí mismos en sus dimensiones individuales y sociales. 
Key words plus

Youth, school, culture and communication.

Mots clés descripteur

Jeune, école, culture et communication.

\section{Abstract}

This article reviews studies that in the last two decades have reflected on youth in school culture from the socio-cultural, socioeducational and sociodiscursive fields. These studies allowed a first approach to the notions of youth, school culture, youth cultural universe, communication and subjectivity. Although the fields are schematically addressed, the paper elaborates on the socio discursive reflection to understand both the social interactions of young people in the communicative level and its relationship with the way these individuals shape their self and way of being at school, as well as how this institution has affected the subjectivities that are built there.

\section{Transfer to practice}

In relation to teaching practices this paper contributes to the search for and construction of a methodological and conceptual proposal that allows, through communication/culture of the image levels, channel processes of diverse subjective configurations in young people. It is a proposal that, in addition to generating methodological and practical changes, seeks that young people, based on symbolic productions, configure their selves and ways of being at school, at school, and recognize themselves from their individual and social dimensions.

\section{Résumé}

Dans cet article de révision on étudie les recherches qu'ont réfléchies par rapport aux jeunes dans la culture scolaire depuis le domaine socioculturel, socioéducatif et sociodiscursif pendant les dernières deux décennies. Ces études ont permis un premier rapprochement aux notions de jeunes, culture scolaire-univers culture juvénile, communication et subjectivité. Même si les domaines ont étés abordés de manière schématique, on a approfondie dans la réflexion sociodiscursive pour comprendre tantôt les interactions sociales des jeunes dans le plan communicatif et leur rapport à la manière dont ces individus façonnent leur façon d'être et rester au collège, que la manière dont cette institution a affectée les subjectivités qu'y se construisent.

\section{Transfert à la pratique}

Les implications de ce projet de recherche pour les pratiques pédagogiques se trouvent dans la recherche et la construction d'une proposition méthodologique et conceptuelle qui donne la possibilité au moyen de scenarios communicatifs/culture de l'image, de canaliser les processus de façonnage de subjectivités diverses dans les jeunes de la culture scolaire. II s'agit d'une proposition qu'en plus de produire les changements méthodologiques et pratiques, elle vise que les jeunes, sur la base de productions symboliques façonnent leurs manières d'être et rester au collège, et qu'ils puissent se reconnaitre à euxmêmes depuis les dimensions individuelles et sociales.
Palavra-chave descritor

Jovem, escola, cultura e comunicação.

\section{Resumo}

Este artigo de revisão estuda as pesquisas que nas últimas duas décadas refletiram sobre os jovens na cultura escolar desde os campos sociocultural, socioeducativo e sociodiscursivo. Referidos estudos permitiram uma primeira aproximação às noções de jovens, cultura escolar-universo cultural juvenil, comunicação e subjetividade. Ainda que os campos sejam abordados esquematicamente, aprofunda-se na reflexão sociodiscursiva para compreender tanto as interações sociais dos jovens no plano comunicativo e sua relação com a forma como estes sujeitos configuram sua forma de ser e estar na escola, como a maneira em que esta instituição tem afetado as subjetividades que ali se constroem.

\section{Transferência à prática}

As implicações deste projeto investigativo para as práticas pedagógicas têm relação com a busca e construção de uma proposta metodológica e conceitual que permita através de cenários comunicativos/cultura da imagem, canalizar processos de configurações subjetivas diversas nos jovens da cultura escolar. É uma proposta que, além de gerar mudanças metodológicas e práticas, procura que os jovens, sobre a base de produções simbólicas, configurem suas formas de ser e estar na escola e se reconheçam a si mesmos desde suas dimensões individuais e sociais. 


\section{Introducción}

Comprender que la escolarización "'crea juventud', es decir, contribuye fuertemente a la construcción de estos nuevos sujetos sociales" (Tenti, 2000, p. 2), es al mismo tiempo considerar que las instituciones escolares, junto con la familia y los medios de producción, son los tres actores que juegan en la construcción subjetiva de los jóvenes. Estas palabras del sociólogo argentino resultan cruciales para introducir este texto, pues ponen en discusión la construcción subjetiva de los jóvenes en el escenario escolar.

Aunque la juventud como objeto de estudio ha cobrado fuerza desde distintos campos del conocimiento -sociológico, pedagógico, psicológico, comunicativo, entre otros-, la mayoría se ha preocupado por las culturas juveniles y su afectación con los medios tecnológicos y comunicativos, la formación laboral de los jóvenes o la cuestión de la subjetividad política y la garantía y restitución de sus derechos. Y, aunque también se encuentran investigaciones que han abordado las categorías subjetividad, jóvenes, cultura escolar y comunicación, pocas han interpelado sus encuentros y tensiones, por haber sido estudiadas de manera independiente. A este vacío se suman las preocupaciones personales como educadora de jóvenes frente a la desvinculación entre cultura escolar y cultura social juvenil, concretamente en lo que tiene que ver con el vínculo entre la misión de la escuela y las perspectivas de los estudiantes en cuanto a sus dimensiones emocionales y experienciales desarrolladas en su cotidianidad.

Con este trasfondo, se propone la revisión de las investigaciones sobre jóvenes que se han llevado a cabo en el campo sociocultural, socioeducativo y sociodiscursivo, para desarrollar a lo largo del texto los cruces entre las categorías: juventudes, cultura escolar-cultura social juvenil, comunicación y subjetividad. El primer cruce se refiere a la no relación entre cultura escolar y universo cultural juvenil; el segundo, a las condiciones subjetivas relativas a los saberes, los sentidos y las experiencias desde las cuales se construye la formación de sujetos en el entramado social de la escuela; y el tercero, al reconocimiento de una configuración subjetiva de los jóvenes en el plano comunicativo, aprendizaje que genera subjetividades emergentes y subjetividades producidas por la institución.

Antes de introducirnos en el desarrollo de este estudio, es determinante describir el punto de partida para el diálogo entre las categorías planteadas. En este sentido, la cultura escolar 1) se entiende como aquella forma de organización social que tiene lugar en el ámbito institucionalizado de la escuela y 2) se caracteriza por un sistema normativo que disciplina a los sujetos por medio de las relaciones de poder, la estandarización de los saberes (Cajiao, 1995), el atraso como tiempo social de la escuela, la racionalización de las prácticas culturales (Parra-Sandoval, 1996), la desconexión entre la enseñanza y la vida cotidiana y el descontento de los estudiantes con la clase y el profesor (Morant, 2002). Así las cosas, la cultura escolar no les ha permitido a los jóvenes acercarse al mundo del conocimiento, proyectarse social y políticamente ni configurarse de manera subjetiva mediante un reconocimiento de su historicidad que les permita comprender cómo han llegado a ser lo que son (Foucault, 2005). Entonces, la escuela ha ocultado el verdadero ser y estar juvenil, bajo el sujeto escolar "estudiante" y ello ha ocasionado una completa desvinculación entre cultura escolar y cultura social juvenil, entre ser estudiante y ser joven, dos roles que no se logran articular de manera satisfactoria.

La subjetividad se constituye en una categoría central de la cultura escolar. Pensar al joven como sujeto inmerso en espacios públicos institucionales, como la escuela, implica dar cuenta de los procesos que lo configuran

\footnotetext{
Descripción del artículo | Article description | Description de l'article | Artigo descrição

Esta revisión se deriva del proyecto de tesis doctoral "Jóvenes en la cultura escolar". Consiste en una mirada desde la comunicación a la relación entre cultura de la imagen y subjetividad, desarrollado en el Doctorado Interinstitucional en Educación de la Universidad Distrital Francisco José de Caldas, Bogotá (Colombia), dirigido por la doctora Sandra Soler Castillo. Desde la revisión de las investigaciones que se han llevado a cabo en el campo sociocultural, socioeducativo y sociodiscursivo, este artículo busca describir los cruces que se dan entre las categorías: subjetividad, juventudes, cultura escolar-cultura juvenil y comunicación. El primero tiene que ver con la no relación cultura escolar-cultura juvenil, el segundo con las condiciones subjetivas relacionadas con los saberes, los sentidos y las experiencias desde las cuales se construye la formación de sujetos en el entramado social de la escuela, y el tercero con el reconocimiento de una configuración subjetiva de los jóvenes en el plano comunicativo.
} 
y reconfiguran: históricos, sociales y culturales. Estos referentes construyen su subjetividad, entendida como producción simbólico-vivencial, desde distintas instituciones y relaciones del sujeto con el otro. De acuerdo con Reguillo, la "compleja trama de los modos en que lo social se encarna en los cuerpos, y otorga al individuo históricamente situado tanto las posibilidades de reproducción de ese orden social, como las de su negación, impugnación o transformación" (2006, p. 61). Es la comprensión del ser humano desde su experiencia cotidiana social y culturalmente afectada, cambiante y complejizada por otros y desde otros.

Observar a los jóvenes en la cultura escolar con esta óptica permite, en ámbitos experienciales y emocionales, interpretar las visiones relacionadas con las formas de ver y sentir el mundo hoy, el mundo juvenil mediado por su familia y sus pares, por pasiones, enamoramientos y deseo de ser alguien en la vida. Singularidades del sujeto que se entrelazan en la cultura escolar y la cultura social juvenil y que se exteriorizan en el lenguaje visual. Un lenguaje que, más allá de mostrar formas de acción, hace posibles procesos de comunicación donde los seres humanos modifican su visión de la realidad y se manifiestan socialmente, cuando, mediante una imagen, dan a conocer su ideología y subjetividad. En palabras de Dussel y Gutiérrez, "vivimos en una sociedad dominada por las imágenes [...] [por ello] aprender a leer esas imágenes y analizar la carga que contienen, 'abriéndolas' hacia contextos más amplios y poniéndolas en relación con otros relatos y discursos que interpretan esa realidad, es una tarea educativa de primer orden" (2006, p. 157). La cultura escolar enfrenta, entonces, el desafío de integrar la cultura de la imagen a los procesos de subjetividad en jóvenes. Reto complejo, debido a que "las instituciones escolares, afincadas en la palabra escrita, tienen dificultades en la medida en que los jóvenes están inmersos en una cultura de la velocidad, de la fragmentación y de la imagen" (Muñoz, 2009, p. 14).

Jóvenes, cultura escolar, comunicación y subjetividad se convierten en categorías que atraviesan este artículo. Categorías que se han venido estudiando de manera independiente en distintos campos, como el sociológico, pedagógico y psicológico, sin llegar a un encuentro sociodiscursivo que comprenda las prácticas comunicacionales que constituyen al sujeto escolar.

\section{De lo dicho y lo no dicho}

No es nada fácil seguir la pista de cómo ha sido pensada y expresada la relación jóvenes-cultura escolar, comunicación y subjetividad, y mucho menos cuando se la concibe con la idea de no reconocer cada categoría de manera independiente, sin comprender los cruces y tensiones que emergen entre ellas. Con esta pretensión se revisan tres campos que han venido reflexionando sobre los jóvenes en la cultura escolar. En primer lugar, se abordan los llamados estudios socioculturales, referidos a las experiencias como elementos que configuran la subjetividad de los jóvenes en la escuela y su relación con escenarios no institucionalizados. En segundo lugar, se examina el campo socioeducativo, es decir, la noción de cultura escolar en articulación con el conocimiento, el poder y las prácticas pedagógicas, para entender el proceso de formación de sujetos en el entramado social de la escuela. Por último, se revisa el campo sociodiscursivo, como una manera de comprender las interacciones sociales de los jóvenes en el plano comunicativo, concretamente en el estudio de su lenguaje oral, escrito, audiovisual y visual en la cultura escolar.

\section{Campo sociocultural. Cultura escolar y cultura social juvenil: ¿encuentros o desencuentros?}

Pareciera una obviedad darle un significado al concepto "joven". Sin embargo, más allá de comprenderlo desde los procesos psicológicos y biológicos de un determinado grupo que se encuentra en un intervalo de edad, y que está constituido teóricamente de acuerdo con unas representaciones impuestas, es necesario complejizar esta etapa a partir de condiciones socioculturales e históricas. Aunque se sabe que existen jóvenes, sujetos que ya no son niños y todavía no son adultos, los límites que concretan los cortes en esta etapa son indefinidos, porque no todos los que tienen la misma edad manifiestan la misma clase de edad o simplemente porque la juventud no es un estado por el que necesariamente pasan todas las personas. Así sostienen Muñoz y Muñoz: "Se ha evolucionado de un modo de ver la juventud como una categoría social universal, hacia una categoría relativa, construida culturalmente; sin desconocer la base biológica y psicológica se enfatiza en los contextos históricos y socioculturales" (2008, p. 221). Con la intención de no entrar en tal debate teórico, en este escrito se habla de "condición juvenil", constituida por distintas circunstancias y dimensiones de la vida social, dadas por el contexto donde se desenvuelve cada sujeto. Esta será la concepción que aquí se manejará para comprender cómo son asumidos los jóvenes en la cultura escolar, específicamente en la escuela secundaria.

Los sociólogos franceses Dubet y Martuccelli (1998), después de una investigación de tres años y retomando el tema de la sociología educativa presente desde Durkheim, realizan una propuesta de experiencia escolar centrada en la relación actores sociales y sujetos de integración social por medio de la formación escolar. Siguiendo un proceso de socialización y subjetivación, establecen una distribución escolar entre 
niños y adolescentes, marcada por su período de escolarización, en la cual un alumno de la escuela primaria es diferente de uno de secundaria. En la escuela, mientras el niño tiende a interiorizar las normas, identificándolas con la autoridad del maestro como algo natural, el mundo colegial de los jóvenes está regido por la percepción de que la autoridad del maestro no es suficiente para legitimar las normas, además de que existen diversos ámbitos de justicia; así, las reglas difieren de acuerdo con los escenarios donde se apliquen.

Bajo la premisa de que los adolescentes en el colegio viven la experiencia de tensión entre ser estudiante y ser joven, Dubet y Martuccelli sostienen que la subjetivación de los jóvenes colegiales nunca se expresa de manera directa, porque en el colegio se configura una cultura escolar opuesta a la cultura juvenil; es decir, se desarrolla una subjetividad no escolar, entendida como un sí mismo no escolar, una subjetividad y una vida colectiva independiente de la escuela, que afectan a la vida escolar misma. Los estudiantes inician la construcción de una subjetividad débil al tratar de imitar lo que hacen los demás, lo que es interpretado por los autores como "una moratoria defensiva". De este modo, la subjetividad de los estudiantes no se expresa de manera directa al estar mediatizada por un "juego del rostro", comportamiento enfocado hacia la exteriorización y, al mismo tiempo, la protección de la intimidad. Así, la construcción de la experiencia escolar "se presenta como una prueba en la cual los actores, especialmente los alumnos, están obligados a combinar y articular diversas lógicas de acción" (Dubet y Martuccelli, 1998, p. 83), desde la interiorización de una obligación hasta la percepción de su utilidad tanto escolar como social. En este escenario, la vida personal se ve afectada por las experiencias escolares a las cuales está ligada, relación que cuestionan los jóvenes al enfrentar la separación entre esta y la escuela.

Para Dubet y Martuccelli (1998), los estudiantes se constituyen como sujetos desde la inversión de tiempo en determinadas tareas escolares, con miras a su utilidad social y a la afirmación de sus gustos, intentando reconocerse como sujetos de socialización al seleccionar las oportunidades educativas a su alcance. De ese modo, la cuestión de los sentidos atribuidos por los jóvenes a la experiencia escolar es central.

Ahora bien, se identifican factores que ponen en crisis los viejos dispositivos que organizan la cultura escolar -como los cambios sustanciales que ha sufrido el poder entre jóvenes-adultos- y el sentido de la escuela en medio de condiciones sociales - como la obligación, ligada a una condición de edad, no a una elección-, la razón instrumental -como garantía de éxito escolar y además laboral-y el amor al conocimiento, considerado el mejor recurso para el éxito escolar. En este sentido, Tenti (2000) expone que en la actualidad no se puede concebir el mundo de la escuela separado del mundo de la vida, ya que los jóvenes traen consigo su lenguaje y su cultura. Así, mientras las instituciones escolares mantienen una mirada sistémica y homogénea, las nuevas generaciones son portadoras de culturas flexibles e inestables. "Bajo estas condiciones, es probable que surjan tensiones entre la integración de los adolescentes a su 'grupo de iguales' y su integración a las normas escolares. Cuando la distancia entre la cultura social incorporada por los muchachos y la cultura escolar-curricular es grande, el conflicto es un fenómeno muy probable en la experiencia escolar" (Tenti, 2000, p. 6).

Desde su universo sociológico, este autor, al mismo tiempo que reconoce la escuela como una institución flexible y abierta a los intereses y conocimientos de los jóvenes como protagonistas y sujetos de derecho, afirma que "los jóvenes son portadores de una cultura social hecha de 
conocimientos, valores, actitudes, predisposiciones que no coinciden necesariamente con la cultura escolar y, en especial, con el currículo o programa que la institución se propone desarrollar" (p. 5). Esta premisa tiene ciertas coincidencias con la tesis de Muñoz (2009), quien establece diferencias entre cultura escolar y cultura juvenil. Este autor devela un tránsito entre los espacios institucionalizados -como la familia, la escuela y el trabajoy los espacios y tiempos cotidianos -como la calle, el barrio y el grupo de pares-, escenarios en donde los sujetos se constituyen como jóvenes. Frente a la caracterización que hace el autor de las nuevas subjetividades móviles, flexibles y mutantes, reconoce que los jóvenes llegan a la escuela como portadores y transmisores de nuevas identidades, propias e impropias, que han sido estimuladas por los medios de comunicación. Ante estos cambios, propone que la escuela debe pensar en posibilitar las prácticas desde la experiencia, desarrollar procesos enfocados a una mejor constitución de sujetos que puedan actuar sobre sí mismos para transformar y acceder a cierto modo de ser e interactuar.

En esta relación entre cultura escolar y cultura juvenil hacen presencia otros espacios institucionalizados y no institucionalizados, que sin duda alguna guardan una estrecha relación con la formación de los jóvenes. Gutiérrez desarrolla de manera clara la correspondencia que hay entre estos dos escenarios, a partir de su tesis:

La escuela es, entre otros espacios, como la familia, la sociedad y la cultura, la que apoya la configuración subjetiva de los jóvenes en la medida en que confirma la existencia de "otros" psíquicos, además de ser un lugar distinto y distante de lo familiar, que da pie a la configuración de la identidad [...]. Es la institución escolar la que genera la mediación cultural entre la socialización primaria de la familia y el ingreso a la sociedad, cuya demanda y deseo en los jóvenes se centra en el reconocimiento personal y social (2007a, p. 150).

En el discurso de esta investigadora mexicana se comprende que la escuela, como agencia constructora de subjetividades, tiene una estrecha conexión con otras instituciones, como la familia, los medios de comunicación y el mercado. Sin embargo, la escuela se destaca como el espacio donde el joven se relaciona con sus pares, con quienes se une para soportar la angustia de enfrentarse a su proceso de reconocimiento. Es una idea de mundo expresada en diversas formas de identidad y reconocida por la autora como "cultura juvenil", caracterizada por formas de ser y estar, y que se identifican como grupos juveniles (grafiteros, punkeros, emo...). De esta manera, los jóvenes demandan de la sociedad un reconocimiento, expresado en sus espacios inmediatos, como la escuela, lo que les convierte en un componente esencial de la construcción social y productores de la subjetividad.

Por otro lado, Gutiérrez (2007a) sostiene que, en la actualidad, bajo la presión del discurso sobre la preparación para el desempeño social y la vida laboral, el joven desarrolla una subjetividad en riesgo, marcada por el desaliento frente a un presente en peligro que lo lleva a una pérdida de su autoestima, a sentirse improductivo y, en el peor de los casos, a encerrarse en sí mismo dentro de una realidad virtual que le ofrece otras posibilidades más atrayentes de ser y estar frente a su presente confuso, como vídeo-juegos, la TV, la música, entre otros medios que hacen parte de "la revolución social-tecnológica a la que asistimos, como parte del cambio de paradigma cultural y la construcción de una nueva subjetividad de los jóvenes" (Gutiérrez, 2007b, p. 68). 
Desde estas configuraciones cada vez más complejas, asumidas por los autores, se aprecia una mirada sociocultural que, además de no desconocer la presencia de la subjetividad de los jóvenes en la escuela, reconoce una puesta en escena personal, una realización de sí mismo a través de la experiencia escolar (trabajo y obligaciones colegiales) que termina ajustándose o desajustándose a la escuela por la experiencia social misma. Se puede afirmar entonces que, tanto para Tenti (2000) como para Gutiérrez (2007a), la familia, la escuela y el entorno social son instituciones que deben cumplir tareas complementarias y simultáneas donde las dificultades de una deben ser suplidas por la otra; de lo contrario, el sujeto entrará en un conflicto que no le permitirá configurarse como sujeto social.

Se aprecia una mirada sociocultural que le apuesta a un vínculo imprescindible entre cultura escolar y cultura social juvenil, en la cual el sujeto se configura como joven cuando tiene la posibilidad de relacionarse con sus pares para compartir preocupaciones en su proceso de reconocimiento y preparación para la vida social y laboral. Es sin duda una búsqueda de identidad que, al mismo tiempo, se relaciona con "una cultura juvenil" y "una cultura escolar", dos escenarios de los cuales surgen relaciones de encuentro, desencuentro y múltiples cuestionamientos. Así lo considera el antropólogo social Feixa:

Las relaciones entre escuela y cultura juvenil pueden equipararse a las que se dan en un matrimonio mal avenido (que se pasa la vida discutiendo aunque no se atreva a divorciarse) o en una pareja de hecho (que no quiere formalizar su relación aunque estén condenados a convivir). La escuela mira a la cultura juvenil con temor y suspicacia, y a su vez la cultura juvenil mira a la escuela con animadversión y rechazo. Pero también hay momentos en que una y otra se miran cara a cara y establecen relaciones fructíferas (2010, p. 8).

Feixa logra moverse en esta tesis a partir de la ruptura que establece con los tres modelos tradicionales de transmisión cultural propuestos por Margaret Mead (1970) -la escuela posfigurativa (donde los adultos educan a los jóvenes), la escuela cofigurativa (donde los jóvenes se educan entre ellos) y la escuela prefigurativa (donde son los jóvenes quienes empiezan a educar a los adultos)-, para plantear su propuesta desde tres momentos distintos: 1) escuela posfigurativa (de principios del siglo xx), cuando en Alemania se sientan las bases para una reforma educativa que integre la cultura juvenil en la llamada "comunidad escolar libre". Esta aparece como una unificación de la escuela del trabajo y de la escuela cultural, que buscaba integrar las innovaciones de algunas escuelas culturales de las élites con los avances democratizadores de la escuela pública popular; 2) escuela cofigurativa (de mediados del siglo XX), cuando en Estados Unidos se produce el auge de la high school, para introducir en el sistema escolar la sociedad adolescente, en el cual los jóvenes hablan un idioma diferente al de los adultos. Esta escuela secundaria se convirtió en el centro de la vida social de una nueva categoría de edad, que importaba más que la clase social, y en el que no solo ofrecía una categoría académica, sino un espacio social compuesto por una serie de rituales (clubes, películas, bailes, fiestas...); 3) escuela prefigurativa (presente), de aprendizaje en red, o escuela digital, donde los jóvenes sobrepasan a los adultos en el mundo tecnológico y logran un desplazamiento en otros campos.

En este repaso, Feixa concluye que la cultura juvenil nunca ha sido una cultura pasiva, por eso es receptiva a otras instancias como la escuela, el mercado, los medios, donde, además de construirse muchos elementos propios del universo cultural juvenil, el joven ha podido instalarse cómodamente mediante el encuentro dialógico con sus pares que hablan el mismo lenguaje y practican normas diferentes a las de la sociedad adulta. En este sentido, es necesario que en la escuela y directamente desde el currículo, además de romper las relaciones jerárquicas entre el adulto que enseña y el joven que aprende, se comprenda el lenguaje simbólico que caracteriza la vida cotidiana de los jóvenes: la música, las tecnologías, los objetos, como elementos que muestran sus formas de ser, pensar y sentir.

Reyes también reconoce la experiencia estudiantil y experiencia social de los jóvenes como dos prácticas que se alimentan mutuamente y se afectan, porque "los sujetos adolescentes construyen la experiencia estudiantil en relación directa con las instituciones educativas, pero no aislada de las relaciones, estrategias, ni de las perspectivas que tienen sobre el mundo social en su conjunto y sobre sí mismos dentro de este" (2010, p. 2). Esta mirada deja ver que el universo cultural juvenil y la cultura escolar fusionan de manera diversa: ser joven y ser estudiante, dando lugar a distintas dimensiones en la configuración de cada sujeto.

Los estudios señalados sobre cultura escolar -Françoise y Matuccelli (1998), Tenti (2000), Muñoz (2009), Gutiérrez (2007a), Feixa (2010) y Reyes (2010)basan sus explicaciones en dos argumentos: por un lado, la escuela desarrolla una cultura escolar que configura nuevos sujetos sociales con una subjetividad propia de los jóvenes bachilleres, y por el otro, los jóvenes están influenciados por una subjetivación no escolar, comprendida como el universo cultural que no coincide necesariamente con la cultura escolar. Estas construcciones, aunque diferentes en sus intereses y 
expectativas, no son dos estructuras independientes. Desde esta relación, se identifican dos miradas: la primera muestra ambas culturas como grupos que se configuran en espacios y tiempos distintos y la segunda privilegia un vínculo necesario entre cultura escolar y universo cultural juvenil. Es una relación de no relación que deja ver cómo la existencia de una cultura escolar normalizadora no permite una interacción social con las vivencias, necesidades y expectativas de los jóvenes. Esta premisa muestra la necesidad de construir miradas en un encuentro dialógico entre cultura escolar y universo cultural juvenil, en el cual se profundice en los principios de participación sociocultural y sociopolítica.

A partir de la comprensión de esta postura epistemológica, como primer cruce que atraviesa este estudio, se determina la configuración del sujeto juvenil mediada por una relación imprescindible entre espacios institucionales (familia, escuela y trabajo) y tiempos no institucionalizados (barrio, calle y grupo de pares). Así, la experiencia estudiantil se considera como una experiencia social que se construye intersubjetivamente en espacios sociales, culturales e históricos.

\section{Campo socioeducativo. Producción subjetiva e intersubjetiva del joven en el entramado social de la escuela}

En el campo socioeducativo, el primer trabajo sistemático en Colombia en estudiar de manera rigurosa los comportamientos y la dimensión social de la vida juvenil en la escuela fue realizado por Parra-Sandoval en compañía de Cajiao (1995) en la investigación "Proyecto Atlántida: adolescencia y escuela: una mirada desde la óptica de los adolescentes de educación secundaria en Colombia". En esta, los autores consideran que la escuela, como sistema organizado de modelos de comportamiento ligados a patrones morales y estándares académicos, se convierte en una institución con atraso social, que fragmenta el mundo de la vida juvenil y el mundo adulto propio de los profesores. Estas dos últimas características se consideran las dos premisas fundamentales que atraviesan su trabajo. En la primera premisa -"el atraso es el tiempo social de la escuela"se reconoce que si bien Colombia ha pasado en las últimas décadas por un proceso de modernización, "en contraste, la escuela se ha quedado rezagada reproduciendo un modelo arcaico expresado básicamente en dos aspectos: en la concepción y práctica del conocimiento y en la organización social de la escuela" (p. 23). El primer aspecto está relacionado con una distribución de la información que no logra procesarla, porque se dejan de lado procesos pedagógicos que terminan por convertir la escuela en una institución socialmente ineficaz. Y, en cuanto a su organización social, se basa en un esquema que gira en torno al poder del maestro, sin darles participación democrática a otros estamentos de la comunidad (alumnos, padres). La segunda premisa -"hay una ruptura marcada entre el mundo adulto y el mundo de los adolescentes"- origina dos culturas delimitadas por la infantilización que hacen los maestros de los adolescentes, como una forma de perpetuar su poder y de no involucrarlos en la actividad social.

De esta contextualización se infiere que la escuela no se comprende como un acontecimiento educativo, sino más bien como uno moral y político, que adopta una serie de instrumentos (examen, vigilancia, sanción normalizadora) para garantizar la prolongación y el encauzamiento de la infancia (Foucault, 1990). Por otro lado, se reconoce que la cultura de los jóvenes está influenciada por culturas variables vinculadas a la cultura global nacida de los medios masivos de comunicación y los avances tecnológicos: "Es entonces fácil percibir el abismo que se abre entre la lenta cultura premoderna de la escuela y la intensa rapidez de la posmodernidad que se vive en el universo cultural de los adolescentes" (Cajiao, 1995, p. 25). La aparición de los medios masivos de comunicación, sumada a un modelo de comportamiento impuesto por los adultos que no responde a las expectativas de los jóvenes, se convierte en una situación problémica que complejiza la vida social en la escuela. Se trata de una mirada negativa y arcaica descubierta por los mismos jóvenes con respecto a la capacidad de la escuela para acercarlos al mundo del conocimiento. Más adelante, Parra-Sandoval (1996), apoyado en estudios empíricos, logra desarrollar esto con mayor precisión a través de un acercamiento a la categoría "cultura escolar", comprendida como:

Las formas de organización social de la institución escolar; los valores y normas que la informan el concepto y manejo del poder, de la participación, de la solución de conflictos; las reglas que rigen la violencia; las relaciones entre maestros y alumnos; la disciplina; la naturaleza del conocimiento y la manera de tratarlo. La cultura escolar es tal vez el instrumento pedagógico más complejo y poderoso con que cuenta la escuela no solamente para llevar a cabo su trabajo en el campo del conocimiento sino fundamentalmente para ejercer su labor de formadora de ciudadanos. La cultura escolar se expresa en la vida cotidiana y es en esa vida, y no en los discursos escolares sobre la democracia, donde se crean y refuerzan valores, normas y formas de ver y vivir la vida (p. 227).

Esta apreciación interpela e invita a la reflexión sobre los efectos de la organización social de la escuela en lo que respecta a la formación del sujeto. El primer efecto de esa forma de organización escolar tiene que ver con una fractura científica entre la teoría 
y la práctica, que refuerza la memorística $-y$ no la participación del joven, al creer que el conocimiento ya está hecho- y no alienta a pensar científicamente. Como segundo efecto, está la desigualdad social inducida por la escuela y la modernización, que han generado la intensificación del desarrollo desigual dentro de las ciudades más modernizadas, al dar menos saberes eficaces a quienes más los necesitan. Y el tercero se relaciona con la formación de ciudadanos, enmascarada en el discurso de la democracia, el gobierno escolar y una organización social afincada. Esta última fractura se manifiesta, según Parra-Sandoval, en elementos como el poder y la participación, los valores ciudadanos y la violencia escolar. Desde este escenario, este autor logra comprender que no existe una relación entre el discurso y la vida, dos mundos independientes, resultado de "la fractura pedagógica que tiene la capacidad de permear toda la cultura escolar" (Parra-Sandoval, 1996, p. 230).

Este quiebre que atraviesa la cultura escolar deja ver, además de la relación de la escuela con la sociedad que se moderniza, que la escuela no cumple eficientemente su función de formar ciudadanos. La no relación escuela-sociedad entre el discurso pedagógico y la práctica pedagógica centrada en su eficacia y desarrollo interno se construye mediante lo que el autor llama "estudiante eco", un sujeto que, aunque mediado por herramientas tecnológicas modernas, continúa repitiendo procesos comunicativos tradicionales con palabras ajenas y efímeras. Es la construcción de un sujeto escolar prestado que no refleja el propio ser, sino el de otros.

Estas dos investigaciones permiten percibir que la interacción social del joven en la cultura escolar -caracterizada por el disciplinamiento de los sujetos a través de pautas dominantes entre adulto-joven, el atraso como tiempo social de la escuela y la desigualdad de acceso al conocimiento - le ha generado cierta incertidumbre frente a la construcción de su historia personal y profesional. La escasa pertinencia de la escuela colombiana para dialogar con la cultura contemporánea no responde a las expectativas de los jóvenes frente al aprendizaje, la formación y la participación.

Desde una perspectiva europea, las investigaciones de Forquin (1989), Chervel (1998), y Rodríguez Lestegás (2006) hacen aportes fundamentales al concepto de "cultura escolar" en relación con la construcción social de las disciplinas escolares. Para Chervel (p. 68), la cultura escolar crea una serie de estrategias de enseñanza y disciplinas escolares -conocimiento escolar propio-que, al mismo tiempo que organiza la distribución del tiempo escolar y la relación de los alumnos con el conocimiento, responde a una de las finalidades de la escuela: asumir funciones de aculturación en la transmisión de saberes de una generación a otra; es decir, vehicular una cultura particular, denominada por este autor "cultura escolar".

En este sentido, la cultura escolar abre paso al conocimiento geográfico escolar como "uno de los instrumentos elegidos para generar un objeto de enseñanza capaz de construir un nuevo imaginario europeo por encima de los estereotipos, de los antagonismos, de la compartimentación política del espacio y de los continuos enfrentamientos armados entre los diversos pueblos del continente" (Rodríguez L., 2006, p. 846); es decir, la geografía como disciplina busca desempeñar una función ideológica al servicio de unidad territorial y la construcción de identidades nacionales. Así, se desarrolla un currículo con una fuerte orientación academicista y culturalista, a través del libro de texto como instrumento esencial para organizar el conjunto de conocimientos impartidos de profesores a alumnos como reproducción simple y objetiva de la realidad del mundo (p. 840). En esta proximidad escolar a la geografía se aprecia un interés predominante por el conocimiento disciplinar, por rechazar lo político, enseñar resultados realistas y construir un referente consensuado que conduzca a una concepción general del mundo.

Desarrollar el sentimiento de identidad y explicar el continente europeo como concepto cultural se ha convertido en pieza clave de la normativa que rige la enseñanza, de ahí que la prioridad de las demandas políticas e institucionales sea proporcionar a los jóvenes los recursos necesarios para comprender a Europa, sin brindarles espacios para ubicarlos como protagonistas de situaciones sociales globales y usuarios de códigos culturales. En este panorama, se puede apreciar que la escuela en España, al igual que en Colombia, ignora la transmisión y construcción de conocimientos mediante diversos lenguajes y en distintos escenarios, lo que genera una gran dificultad para comprender las nuevas experiencias, formas de ser y estar en el mundo, es decir, lo que caracteriza las subjetividades juveniles, que solo pueden ser comprendidas en los ámbitos de contexto de la sociedad a la cual pertenecen: el mundo global, nacional, local, y el entorno más inmediato que circunda esa realidad: la familia, la escuela, el grupo de amigos.

Se puede apreciar, entonces, que Rodríguez Lestegás (p. 853) cuestiona la cultura escolar repensada en la geografía en cuanto disciplina escolar limitada a contenidos en clave europea. Así las cosas, es importante comprender que cada época le atribuye a la escuela una misión distinta, lo que indica que la transmisión de conocimientos y las maneras de ver y representar el mundo son diversas en cada nación y en cada momento histórico. Dicho esto, la cultura escolar está vinculada a determinadas representaciones culturales que exigen un compromiso por parte de la escuela; 
una mirada que, más allá de profundizar en contextos históricos y geográficos, reflexione sobre el reconocimiento de los jóvenes como sujetos sociales inmersos en valores culturales que configuran sus formas de saber, ser y estar, pues no hay que olvidar que "las concepciones de los estudiantes [...] proceden de fuentes diversas, de las cuales los conocimientos académicos solo representan una de ellas" (p. 852).

En esta construcción también ejercen gran influencia los estudios latinoamericanos recopilados desde Argentina sobre la escolarización de los adolescentes, compendio realizado por el IIPE-Unesco, cuyo objetivo es aportar elementos que permitan entender mejor las características de la relación entre las actuales generaciones protagonistas de un aprendizaje compartido, reconociendo a la escuela como una de las principales instituciones donde los jóvenes interactúan y conviven de manera pasional y cotidiana.

En las exposiciones se encuentra la mirada antropológica social de Levinson (2012), quien, a partir de investigaciones empíricas realizadas en México, combinadas con su papel de educador de jóvenes, se pregunta por qué sigue habiendo una brecha tan abismal entre la expectativa del joven y la oferta de la escuela. Como punto de referencia etnográfica ha estudiado la problemática desde la perspectiva de los estudiantes y los padres, hasta los puestos de poder en un sistema educativo, y encontró que los mismos procesos de globalización, de usos tecnológicos, han aportado a la configuración de nuevas identidades construidas en torno a ciertos gustos que ya no corresponden a anteriores características dadas por la clase social, la nacionalidad o etnicidad; es decir, la cultura juvenil sigue pluralizando y tomando nuevas formas.

De los aportes de Levinson (2012) se logra abstraer, en términos socioeducativos, la importancia que les asigna a la identidad y al sentido de pertenencia a una sociedad. Desde esta premisa, en la comprensión del entramado social de la escuela propone el reconocimiento del joven como sujeto de derecho, inmerso en procesos de globalización y democratización dentro de la "cultura estudiantil". Esta categoría que emerge en su investigación no está enfocada a conocer las formas de comportarse de los estudiantes, se trata más bien de "un acervo de significados y prácticas que se produce históricamente y que se transforma en tanto se adecue por los estudiantes a las situaciones escolares particulares [...] son recursos simbólicos a los que recurren los estudiantes para resolver sus problemas y construir su identidad" (p. 90). En este sentido, Levinson comprende la cultura estudiantil como los recursos comunicativos simbólicos que encuentran y utilizan mutuamente los estudiantes y, en algunas ocasiones, con los maestros, para acomodarse a las situaciones escolares cotidianas y, así mismo, aprender a ser cier- to tipo de personas para sus vidas posteriores y para su configuración como sujetos sociales. Así, la cultura estudiantil propone y dispone de identidades que se constituyen parcial o totalmente dentro de la escuela; al mismo tiempo, es en esa comunidad de los estudiantes de "la escuela" donde se constituye todo un aprendizaje de ser y estar. Las investigaciones realizadas por Rockwell (2010) y Milstein, Clemente, DantasWhitney, Guerrero y Higgins (2011) guardan estrecha relación con esta postura, por mostrar complejidades y contradicciones de la vida cotidiana de las escuelas y reflexionar sobre cómo en esta institución los alumnos le dan sentido a su experiencia.

Paralelamente, el profesor Pereira (2012), a través de diálogos juveniles sobre la educación secundaria en Brasil, aborda un interrogante clave para los alumnos: ¿Qué es necesario transformar en su escuela para que la misma pueda contribuir con sus planes de vida? Guiado por esta cuestión estudia la relación entre los jóvenes y los procesos educativos, a partir de una perspectiva que rompe con visiones preconcebidas sobre la juventud; por eso comprende esta categoría como "condición juvenil". Reconoce que la institución se enfrenta con un nuevo perfil de alumno, con otras culturas y prácticas sociales. No es el alumno ideal marcado por la identidad de estudiante adecuado a las reglas y normas escolares; por el contrario, es un alumno cambiante en el tiempo. A la vez, el autor encuentra en la escuela pública una pedagogía de la precariedad, porque entre los jóvenes se alimenta el sentimiento de que sus proyectos de vida están construidos sobre la incertidumbre. Pereira llega a la comprensión de cómo los jóvenes sienten la escuela y se sienten en ella, y confirma que las motivaciones y los sentidos que se relacionan con la escuela resultan de la combinación entre las relaciones sociales en que los jóvenes se insertan y aspectos personales que muchas veces tienen que ver con la retribución a la familia.

De estos hallazgos del autor logra emerger la categoría de "sentido o identidad" en las instituciones educativas, por lo que comparte a la vez la postura de Abrantes \& Da Costa (2003), quienes consideran la escuela como contexto fundamental donde los jóvenes llegan en busca de un sentido para la vida, también reconocido como identidad. Así, Pereira propone construir una escuela para todos, donde se le dé sentido a la configuración alumno-joven. Paralelamente, devela que la escuela también busca un sentido para sí, y encuentra que "en el plano de las identidades juveniles, sentido puede comprenderse como el rumbo que la escuela le da a la vida de los jóvenes" (p. 116).

En esta mirada socioeducativa, el discurso de Levinson (2012), Rockwell (2010), Milstein et al., (2011), Pereira (2012) y Abrantes \& Da Costa (2003), comparado con el de Parra-Sandoval (1996) y Cajiao (1995), a 
pesar de la diferencia temporal y espacial, y aunque lo expongan de manera distinta, deja ver que en Latinoamérica existe una coincidencia en la producción subjetiva e intersubjetiva del joven en el entramado social que se teje en la escuela. Se encuentra la necesidad de indagar cómo la escuela y los maestros buscan formas de adentrarse en la cultura estudiantil para relacionarse con sus experiencias, sus expectativas y sus formas simbólicas de comunicarse, elementos estos que responden a dos intereses por parte de los jóvenes. Por un lado, a querer avanzar profesional y económicamente "para ser alguien en la vida" y, por el otro, al placer social o autoestima producido dentro de la escuela para sentirse aceptado por el "otro". Son dos situaciones que, además de buscar acabar con la desigualdad social, no tienen una estrecha relación con los contenidos.

De lo dicho se puede inferir que las subcategorías que surgen en este campo -"cultura estudiantil" (Levinson, 2012) y "sentido o identidad" (Pereira, 2012)- desarrollan el segundo cruce entre las categorías establecidas, que tiene que ver con las condiciones subjetivas relacionadas con los saberes, los sentidos y las experiencias desde las cuales se construye la formación de sujetos. Se comprende, entonces, que solo desde los significados y las intenciones que orientan la acción humana la escuela logra tener sentido, comprendido este como "producción intersubjetiva, procesal y contextual que se revela en las prácticas, símbolos, rituales, instituciones, estructuras" (Pereira, 2012, p. 116). Es decir, el entramado de sentidos que se constituye en la cultura escolar, además de ser un referente para comprender el sentido de los actos, se teje en los contextos que construyen las relaciones históricas, socioculturales y comunicativas del sujeto.

Por otro lado, con una mirada política enmarcada en el enfoque socioeducativo, la pedagoga argentina Tiramonti (2012) destaca el valor de encarar la indagación y orientarla al diseño de políticas exitosas para transformar la escolarización de los jóvenes en un trayecto significativo para su incorporación al diálogo social. La representación que hace del futuro le permite ubicar a los jóvenes en procesos culturales y hacerlos protagonistas del manejo de códigos culturales que tienen muy poco que ver con el universo simbólico que proporciona la escuela. Sus investigaciones muestran una decadencia de esta institución -que resulta de un proceso de cambio social, en cuanto su dificultad para planear el futuro de los alumnos-, expresada en elementos como "la primacía de los medios de comunicación masiva y las identidades que se forjan a la luz de la pertenencia a redes sociales y grupos de pares, que tienen una capacidad de regular gustos, comportamientos y modos de vida de los jóvenes" (p. 180). Al mismo tiempo que esta investigación muestra esfuerzos por explicar el desdibujamiento de la escuela frente al futuro de los jóvenes, refuerza la necesidad de replantear los dispositivos en que ha caído esta institución (imposición de horarios, legado de los adultos, saberes tradicionales) con la intención de proponer un mecanismo que organice los contenidos acordes a las necesidades de la contemporaneidad. Y, así mismo, ratifica que el trabajo escolar no debe separar el mundo de vida de los jóvenes y la existencia de la conformación de subjetividades, que son objeto de la transmisión cultural de la escuela y el supuesto "juvenil" (Berardi, 2007).

\section{Campo sociodiscursivo. Una manera de comprender la configuración subjetiva del joven en el plano comunicativo}

El campo sociodiscursivo, además de capturar el mayor interés en este artículo, es uno de los que más amplio desarrollo ha tenido en investigaciones empíricas relacionadas con las configuraciones e interacciones 
subjetivas del joven en la escuela. En este campo se encuentran los estudios sobre los jóvenes en relación con: los distintos aspectos del lenguaje verbal, oral o escrito, siendo este el de mayor uso; los medios masivos de comunicación o audiovisuales; y, por último, el lenguaje visual, que han sido los menos explorados.

Lo oral y lo escrito, piezas clave en el mundo del joven escolar

El "lenguaje juvenil" es un eje que atraviesa en todas las direcciones el plano comunicativo del joven. $Y$, al tiempo que designa un conjunto de rasgos presentes en sus manifestaciones lingüísticas producidas en forma oral o escrita (Herrero, 2002), surge como una pluralidad de variedades juveniles (sexo, grupos específicos) mediadas por factores sociales, culturales y geográficos, asociados con el factor edad (Zimmermann, 2002). Desde esta postura se sigue que no se puede hablar de un lenguaje juvenil escolar homogéneo, ya que el factor edad se mezcla con otros y genera variables, como lenguaje juvenil femenino, lenguaje juvenil marginal, lenguaje juvenil de diferentes culturas juveniles, entre otras.

Para profundizar en la caracterización del lenguaje juvenil como manifestación sociodiscursiva, conviene mencionar que, a pesar de los trabajos vanguardistas del mundo hispánico realizados por Barker (1950) sobre el lenguaje de los jóvenes pachucos en el sureste de Estados Unidos, este ha sido visto como marginal, debido a que es un grupo social que de manera equívoca se ha considerado como tal, según Zimmermann (2002), en consideración a dos aspectos: primero, que la juventud no representa ningún factor de poder socioeconómico y, segundo, que el lenguaje juvenil, al considerarse una moda, tiene muy poca supervivencia, por su variación respecto al tiempo y al espacio. En estas variaciones juega un papel determiante la escuela, por ser este un escenario de convivencia de subculturas donde se da una variedad social de la lengua, un sociolecto. Para centrar la atención en el lenguaje juvenil escolar, unido a lo cotidiano, tanto institucional como inscrito en otros escenarios, conviene prestar atención a los aportes de Rodríguez (2002) y Morant (2002), fruto de investigaciones relacionadas precisamente con "el lenguaje de los jóvenes".

Rodríguez (2002) considera que, para la sociolingüística, el lenguaje de los jóvenes es importante, especialmente cuando están solos y entre sus pares, por ser este el espacio donde muestran un estilo natural. Destaca, además, que si los jóvenes pertenecen a una subcultura, desarrollan un lenguaje especial (sociolectos), acompañado de argots marginales, caracterizados por un vocabulario reducido y falta de creatividad léxica. El uso del argot entre jóvenes evidencia el sentido de grupo, y está influenciado por los lenguajes marginales, pero también se impregna del léxico de los jóvenes de mayor nivel social y cultural. La variación ligüística refleja algunos elementos, como el estatus socioeconómico, la etnia, la religión, la profesión, la edad, siendo esta última la variable que más tiene en cuenta una persona en interacción verbal. Al mismo tiempo, Rodríguez sostiene que el aporte de los medios de comunicación aumentó nuevas expresiones de moda, las cuales imponen una comunicación rápida, efectiva y cifrada.

En lo que respecta al leguaje de los jóvenes en la cultura escolar, este autor considera que hablar del lenguaje de los estudiantes es casi sinónimo del lenguaje juvenil y afirma que algunos de los trabajos publicados con este nombre han sido desarrollados a partir de datos escolares. Sin embargo, reconoce que existe un lenguaje específicamente estudiantil, cuya función de idenificación grupal, según la mirada sociolingüística, conserva una estrecha relación con los argots maginales. Morant (2002) desarrolla con mayor presición esta variable en un análisis minucioso de frases utiliza- 
das por los alumnos y logra un estudio lingüístico que le permite describir la vida de los jóvenes en la escuela y su forma de ver el mundo. Destaca que uno de los sentimientos que el joven vive con mayor intensidad es el amoroso; emociones que comparte con los compañeros, quienes tienen una gran influencia sobre sus vidas. "De hecho algunos estudiantes afirman que por lo único que vale la pena ir a clase es por los compañeros" (p. 244).

Para Morant (2002), los estudiantes identifican una serie de obstáculos que muchas veces han llevado a que dejen la escuela. El primero está relacionado con la ley que los obliga a asistir a un centro educativo hasta cumplir con la enseñanza secundaria obligatoria; el segundo tiene que ver con la presión que ejercen los padres sobre ellos para que asistan a la escuela; y el tercero se relaciona con la desconexión que hay entre la enseñanza y la vida cotidiana. A esto se suma la mala imagen que los estudiantes tienen de algunos docentes, por su carácter autoritario e impositivo para lograr hacer cumplir los deberes. Sin embargo, también se exalta la existencia de buenos docentes, aquellos que tienen un buen equilibrio entre la exigencia y la comprensión: "Se trata de profesores que se han ganado el respeto de sus estudiantes porque no agobian, porque son partidarios de clases participativas y conscientes de que se olvida lo que se empolla pero no lo que se descubre o deduce" (p. 248).

Por otro lado, mediante expresiones ingeniosas y humorísticas dadas directamente por los estudiantes, Morant logra explicar la conducta del joven dentro del aula, caracterizada por las continuas burlas a compañeros y profesores, donde se menosprecia, además del aspecto físico, el cumplimiento del deber. Al mismo tiempo, el autor logra explicar las diferentes sensaciones (rabia, impotencia, ansiedad, desconsuelo) a las cuales se enfrentan los estudiantes a la hora de los exámenes, por representarles futuro inmediato y lejano.

Desde el plano comunicativo, en este campo se encuentran características de la cultura escolar que también se reconocen en los estudios ya nombrados, como el descontento que manifiestan los estudiantes frente a la clase y al profesor, la asistencia obligatoria a la escuela, la utilidad laboral de los estudios, la escuela normalizadora e impositiva, además del desdibujamiento de una subjetividad, por mostrar ante los adultos un lenguaje enmascarado. Sin embargo, se destaca que en este campo se representan otro tipo de dimensiones de la experiencia que no están en el plano sociocultural ni en el socioeducativo, relacionadas con aspectos relevantes, como sentir, pensar y actuar (amorosos, emocionales, perceptivos), entre otras piezas claves que responden a una realidad socialmente construida, que le da sentido a la comprensión de la experiencia humana.
Lo audiovisual: dispositivos mediáticos, sociales y politicos

Los medios audiovisuales deben su existencia como disciplina al reconocimiento de que la cultura posmoderna está mediada por el capitalismo de la imagen, que se mueve a altas velocidades en el mundo tecnológico y de la comunicación mediática. La cultura de la imagen (Richard, 2006), que emana del predominio cotidiano de lo visual en las formas de percibir el mundo y de interactuar con él, fluye cómodamente en la vida de los jóvenes, no solo por la seducción que ofrece su inmediato consumo de lo disponible y lo mostrable, sino porque permite su reconocimiento social desde el otro y para el otro. En este escenario, se hace una revisión minuciosa de la obra Educar la mirada. Políticas y pedagogías de la imagen, trabajo realizado por Dussel y Gutiérrez (2006). En él se compila una serie de ensayos construidos en la comprensión transdisciplinar de la imagen y la mirada, en cuanto cuerpos pedagógicos y sociopolíticos que suceden en la vida colectiva y cotidiana dentro y fuera de la escuela: el cine, la televisión, la prensa, el otro. La obra integra el análisis de las características del campo visual actual y sus implicaciones para pensar la educación.

Dentro de los trabajos que relatan diversas experiencias de los jóvenes estudiantes con la alfabetización audiovisual, se encuentra los de Pancani (2006) y Serra (2006). Pancani, a través de una confrontación entre la producción mediática y lo que genera la escuela, devela realidades sobre la vinculación entre los medios de comunicación y los contenidos curriculares, que valora como un lenguaje divorciado: "La escuela no les permite a los alumnos que, desde su propia experiencia, resignifiquen los proyectos culturales que los medios difunden, que centran su atención en el argumento, en los procedimientos de disuasión y persuasión" (p. 272). Por otro lado, Serra lleva a pensar la escuela como espacio subjetivo, donde se puede incorporar el cine a la práctica educativa, por ofrecer acontecimientos reales que sensibilizan y dibujan proyectos basados en una nueva forma de mirar, los cuales penetran la escuela. Esta estrategia pedagógica desde la perspectiva de lo fílmico permite no solo evaluar la escuela, sino también los procesos socioculturales que esta construye, al conectar el currículo con el mundo exterior del sujeto. Es un ejercicio visual que requiere una transformación epistémico-teórica por parte del docente, la cual garantice el encuentro de lo estético, lo político y lo social con las maneras de ver el mundo. Paralelamente, Dussel (2006), a través de una discusión crítica, muestra la necesidad de fortalecer un proyecto de pedagogía visual que oriente la práctica formativa en distintos ámbitos sociales e histórico-culturales. La autora cuestiona los esquemas racionales tradicionales frente a la educación de la sensibilidad y la lectura de otros discursos contenidos en el lenguaje 
audiovisual. Abre la discusión de situaciones surgidas de su compromiso con la investigación socioeducativa a través de la fotografía, los reality shows y las series televisivas para jóvenes.

Estos tres estudios evidencian un desencuentro entre escuela y medios de comunicación, porque esta institución no proporciona las herramientas necesarias para propiciar el diálogo con los medios, la comprensión de sus efectos y el procesamiento de su información, que se expande a altas velocidades. Por el contrario, la escuela, bajo un escenario de vigilancia, muestra lo que a su modo de ver es necesario visualizar y expandir y esto conlleva la no resignificación de la experiencia juvenil, una experiencia dada desde la comunicación mediática, que es hoy la representación más colonizadora.

Por este mismo camino, los trabajos de Antelo (2006), Duschatzky (2006) y Fischman (2006) presentan una construcción de relatos a partir de imágenes, que muestran una producción distinta de saberes expresados directamente por los alumnos. Antelo, desde el vínculo de la domesticación del ojo y la sensibilidad corporal, logra captar un amplio repertorio de experiencias escolares que normalmente son invisibilizadas, por ser asumidas como episodios comunes y efímeros, sin pensar que pueden ser trascendentales en el sujeto que los vive. Desde esta premisa, cuestiona los límites entre la interacción semiótica presente en la escuela (subjetividades) y la relación con el entorno. En este mismo sentido, Duschatzky, mediante el uso del vídeo y la historia de un adolescente que vive la escuela como experiencia de vida, logra explicar los mundos subjetivos de las interacciones que recrean los fenómenos educativos. En este trabajo se relata cómo Marcelo, un alumno con comportamiento inmanejable para los maestros, no manifiesta una subjetividad disciplinada, debido a que "está despojado de los atributos propios de una subjetividad pedagógica". Basado en Foucault (1976), en este trabajo se reconoce a la escuela como institución de encierro, donde se vive el manejo del poder a través de la vigilancia de los cuerpos y la codificación de espacios y lenguajes. Se percibe como una organización que posibilita "una intervención puntual (de diferenciación, de corrección, de depuración, de eliminación) en cada momento del cuerpo; posibilidad de caracterizar, y por lo tanto de utilizar a los individuos según el nivel que tienen en las series que recorren" (Duschatzky, 2006, p. 97). Esta postura muestra la escuela como una de las instituciones que ha dejado ver al joven a la luz de una serie de enunciados escolarizados y prácticas dirigidas, que al mismo tiempo regulan su forma de ser y estar y encauzan su conducta y su aprendizaje.

Por otro lado, Fischman constata como premisa que "es sorprendente comprobar que en Estados
Unidos son muy pocos los trabajos de investigación del área educativa que incorporan lo visual" (2006, p. 235). Por medio de la fotografía, como proceso revelador de imágenes, logra desarticular la realidad mediante la producción de sentidos generados social y subjetivamente. Al mismo tiempo, analiza el valor interpretativo de las fotografías en la vida de la escuela, frente al desafío de desarrollar distintos modos de ver y de abrir posibilidades para emprender nuevas experiencias investigativas.

Los trabajos anteriormente citados muestran: 1) el desdibujamiento de la escuela con relación a los medios audiovisuales y 2) un encuentro tradicional de no relación con el mundo de los jóvenes en lo referente a su no reconocimiento como sujetos sociopolíticos, porque no se prioriza su naturaleza participativa y subjetiva, entendida esta como construcción social constituida. Por otro lado, en sus posturas, los autores denotan un interés por comprender el discurso pedagógico de la imagen, dado desde la educación de la mirada que surge en la dinámica de la acción social y la cultura visual, un gran reto, en una sociedad donde las subjetividades enmarcan su rumbo en el mundo virtual.

Los textos obligan a repensar la pedagogía de la imagen para buscar la construcción de prácticas sociosimbólicas que procuren la participación subjetiva desde lo sensorial. No obstante, se sigue notando un vacío respecto a propuestas que involucren "la materialidad dinámica" (Bolívar, 2002) del joven, porque no se logra penetrar en sus dimensiones personales (afectividad, pasión y emocionalidad), que solo pueden expresarse a través del refugio en el propio yo, en las experiencias vividas mediadas por sus intereses, proceso reflexivo que puede ser relatado desde y para su realidad estética.

Se observa, entonces, que hay un avance significativo en lo que respecta al uso de la imagen mediante elementos mediáticos (blogs, cine, tv, prensa), vistos como estrategia didáctica y no como lenguaje que propone una lectura. En este sentido, se da una carencia de elementos que narren de manera visual al joven en sus formas de ser y pensar, dados por la afectividad y el reconocimiento del otro, en cuanto enclaves semióticos en la construcción de subjetividades.

\section{Relación de los jóvenes escolares con la cultura de la imagen. Una forma de mirar y de mirarse}

En una línea similar a la anterior respecto al proceso de relación del joven con la cultura de la imagen, pero distinta en sus intenciones en cuanto a la configuración del sujeto, se encontraron estudios que giran en torno a los jóvenes como consumidores y productores 
permanentes de los medios de comunicación. Estos dispositivos se reconocen en los siguientes trabajos como escenario de prácticas cotidianas de producción escrita y visual, donde se da paso a las expectativas de los jóvenes, como una forma de "contar una historia que permita a otros contar(se) la suya" (Hernández, 2008, p. 97; citado en Hernández1, 2013, p. 89). En este grupo se inscribe el trabajo Investigar con jóvenes. ¿Qué sabemos de los jóvenes como productores de cultura visual? (2013), donde se recoge el resultado de una serie de trabajos del grupo de investigación Edarte, que dan continuidad al desarrollo de dos proyectos: Jóvenes productores de cultura visual: competencias y saberes artísticos en educación secundaria (Edarte, 2009) e Investigar con los jóvenes: cuestiones temáticas, metodológicas, éticas y educativas (Hernández, 2011). Se trata de un trabajo que representa un conjunto de dimensiones de la experiencia humana, en relación con el análisis de imágenes y prácticas sociopolíticas y culturales, que persigue conformar un mapa específico en producción de cultura visual. En palabras de Aguirre, se trata de

... un mapa que ponga en relación el propio objeto (imagen) visual con las circunstancias de la producción -los ámbitos de aprendizaje, las prácticas de profesionalización y legitimación, etc.-, los regímenes de distribución y los lugares de su difusión -la interacción con otros sistemas de representación, las relaciones con las artes, el uso de la tecnología, etc.-, la construcción de sentidos -la subjetivación, las connotaciones subculturales, las cuestiones de orden estético-, así como las implicaciones sociopolíticas, culturales y, en el caso que nos ocupa, educativas de todo ello (2013, p. 14).

En este pretensioso escenario se encuentra el trabajo de Hernández (2013), quien muestra cómo los jóvenes aprenden dentro y fuera de la escuela en relación con la cultura visual. El autor cumple este objetivo desde la perspectiva de los "alfabetismos múltiples", relacionados por Matthews con "el impacto de la nueva economía y las actuales condiciones culturales" en medio de las cuales las personas han de adquirir su saber, "para dar sentido al mundo, a ellos mismos y a los otros" (Hernández, 2013, p. 85). En este escenario, donde la comunicación está mediada por distintos alfabetismos (visual, auditivo, gestual, corporal), es necesario pensar, además de los contextos, las formas en que los jóvenes inician y desarrollan los procesos de aprendizaje dentro y fuera de la escuela. Para la relación

1 La obra de Hernández (2008) citada es: La investigación basada en las artes. Propuestas para repensar la investigación en educación. Educatio Siglo XXI, 26, 85-118 (N. del E.). entre jóvenes y medios digitales, el autor propone como punto de partida dos modos de acercamiento a la cultura visual: miradas culturales y experiencias de subjetividad. La fusión entre estos dos elementos articula la cultura de participación y establece "ese cruce entre mirada cultural (visualidad) y subjetividad (que dice de quién mira y construye los relatos visuales)" (Hernández, 2013, p. 88).

Aunque en esta investigación se puede percibir una propuesta para el desarrollo de la creatividad y la colaboración entre jóvenes a través de actividades comunicativas, también muestra que los cambios en el uso de las tecnologías no han afectado a la escuela. Esto se debe a que todavía están presentes dos culturas distintas en el uso de los medios en relación con el conocimiento: por un lado, fuera de la escuela, los jóvenes tienen la posibilidad de utilizar múltiples alfabetismos, aunque, debido a la poca orientación, lo hacen de forma fragmentada y dispersa; por el otro, en la cultura escolar, los maestros limitan el conocimiento, al regular el contenido y producto de la información disponible y presentada (Hernández, 2013).

Ante esta tensión, se puede deducir que, los jóvenes aprenden y se configuran a través de procesos de comunicación, dentro y fuera de la escuela. Dicho aprendizaje genera subjetividades emergentes y subjetividades producidas por la institución. ¿Cómo se relacionan estas dos cuestiones, teniendo en cuenta que "el juego de subjetividades, en un proceso dialógico, se convierte en un modo privilegiado de construir conocimiento"? (Bolívar, 2002, p. 43). Esta pregunta, que ha venido generando debate en el campo educativo, además implica necesariamente la comprensión desde la cultura visual, entendida como "la reflexión y las prácticas en torno a las maneras de visualizar las representaciones culturales, y en particular, las maneras subjetivas e intrasubjetivas de mirar el mundo y a uno mismo" (Hernández, 2007, p. 21; citado en Hernández 2 , 2013, p. 182). En este mismo sentido, hay que considerar que, para llevar a cabo procesos de enseñanza-aprendizaje, se debe hablar de desarrollos cognitivos dirigidos por la escuela y desarrollos experienciales construidos dentro y fuera de esta.

En esta misma línea, Montenegro (2013), a partir del estudio crítico de novelas gráficas autobiográficas realizadas por tres de las exponentes más destacadas de este género (Marjane Satrapi, Zeina Abirached y Parsua Bashi), arma una propuesta experiencial donde los y las adolescentes de secundaria se apropian de las obras, hacen una relectura de ellas con base en sus propias historias de vida y transforman esos relatos en una fuente de evocación de sus propias etnografías.

2 La obra de Hernández (2007) citada es: Espigador@s de la cultura visual. Barcelona: Octaedro (N. del E.). 
Así, relatan en clave de obra gráfica sus preocupaciones y sueños como jóvenes, estudiantes o como personas enamoradas. Los relatos gráficos se generan con el desafío de "ser ellos y ellas mismas el centro de las obras, trabajar un relato visual que guarde relación con sus propias experiencias, su vida, pasajes de ella o acontecimientos que los hayan marcado como jóvenes" (p. 177).

Es un trabajo que favorece la empatía con el otro y la comprensión de que lo personal también es político. Esta mirada reconoce a la escuela como "el lugar por excelencia para poder generar estos espacios de encuentro con quienes puedan ayudar a exteriorizar de forma gráfica y artística el pasado de cada uno, nuestras propias vivencias" (Montenegro, 2012, p. 175). Es el posicionamiento de las propias experiencias como elemento central en el momento de aprender. Se considera que, dentro de los trabajos estudiados, este da una perspectiva distinta al planteamiento en cuestión, por ser una investigación crítica y participativa que rescata experiencias de vida y sueños, a través de obras gráficas.

Finalmente, este apartado se completa con el relato de una experiencia llevada a cabo por López (2013), a partir de la cual cuestiona los procesos de mediación pedagógica entre lo que a los jóvenes les gusta hacer y lo que la sociedad espera que hagan. Preguntar a los jóvenes qué desean pintar, mediado por un resultado visual esperado y un compromiso laboral, llevó a este artista a proponer la reinterpretación de obras de arte famosas que consideraba lúdicas. Surgió Guernica, de Picasso, pero en otra versión con nuevos colores y cuerpos más mutilados. En esta investigación, se considera que incorporar en los planes de acción educativa las nuevas prácticas culturales que los jóvenes han adoptado (grafiti, concursos de skate, conciertos de rap) es una alternativa positiva. Y lo es no solo porque "la gran afluencia de jóvenes a estos talleres ha hecho de ellos un punto de encuentro para las diferentes subjetividades que parecieran estar en eterno conflicto con la idea de civismo, arte y escuela que el adulto propone" (p. 172), sino porque es necesario tener un acercamiento a sus experiencias y relatos, no a través de "Guernicas", sino desde su lenguaje simbólico, con sus líneas y formas caóticas, como acto de resistencia. Esta mirada de los jóvenes como parte importante en la producción, más que de imágenes, de significados, es una forma de poner a dialogar las subjetividades emergentes con las impuestas por las instituciones.

De la reflexión en el campo sociodiscursivo surge un tercer y último cruce, interpretado como una fuerte tensión joven-escuela en el plano comunicativo y de uso de los diferentes lenguajes (verbal, visual y medios de comunicación). Dichos elementos no han logrado constituirse en la producción de saberes, la construcción de sentidos y la formación de sujeto, lo que ha generado dos tipos de subjetividades: las emergentes y las producidas por las instituciones educativas. Es una situación de interferencia que muestra un juego de subjetividades en proceso dialógico, que la escuela solapa, pero que la cotidianidad escolar viene visibilizando.

En este cuestionamiento han surgido en el campo de la comunicación/educación posturas como las de Kaplún (1998), Huergo (2000), Martín-Barbero (2003) y Muñoz (2007), quienes proponen nuevos escenarios (mediático-tecnológicos y sociocomunitarios) para los procesos educativos, con la intención de empezar a recuperar en la escuela espacios históricos, socioculturales y políticos. Otras miradas, relacionadas con entornos personales de aprendizaje y nuevas ecologías del aprendizaje en contextos múltiples, como las de Cobo y Moravec (2011) ofrecen ideas novedosas en el cambio de la educación, la comunicación y la estética trasmediática, con una serie de herramientas que facilitan los procesos de aprendizaje transdisciplinar en cuanto a la flexibilidad e innovación, aspecto social y distribución oportuna de la información, a fin de poder ser comprendida y expandida a través de la interconexión, uso que es cada vez es más atractivo y accesible.

Las propuestas mencionadas están enfocadas a que la escuela tenga una visión más amplia de las nuevas tecnologías de la información en los procesos de enseñanza-aprendizaje $y$, además, ofrecen otros discursos que favorecen la recreación de imágenes y sonidos propios de las nuevas culturas emergentes, dentro de la red simbólica de los "lenguajes juveniles", entendidos como vivencias, saberes y visiones de mundo con que ingresan los jóvenes a la escuela.

\section{Consideraciones finales}

Las revisiones en el campo sociocultural, socioeducativo y sociodiscursivo muestran que, en los últimos veinte años, la juventud como objeto de estudio ha cobrado un profundo interés en las ciencias sociales, especialmente en lo referido a las culturas juveniles y los escenarios no institucionalizados donde viven su cotidianidad. No obstante, son escasos los estudios que han abordado a los jóvenes en sus procesos de subjetividad y su relación con las dinámicas construidas en la cultura escolar y otros escenarios significativos para ellos, como es la cultura de la imagen en la era digital. Las investigaciones revisadas revelan que la escuela aún refleja mandatos burocráticos en los que se imparten conocimientos estandarizados a través de medios autoritarios que disciplinan. Por otro lado, los trabajos estudiados, unos enmarcados en teorías pedagógicas 
generales y otros en estudios culturales, muestran que la cultura escolar no ha establecido una relación de confluencia entre prácticas educativas y culturales, debido a que la escuela no ha logrado concebir que "la juventud como fenómeno social sólo puede ser definida en términos de cultura" (Merino, 2010, p. 57). Es decir, las instituciones educativas siguen valorando al joven en su rol de estudiante, dado por procesos académicos y de convivencia, sin atender a sus realidades sociales, culturales y comunicativas, producto de cada época y contexto.

Con este trasfondo, y con el desarrollo minucioso en diversos campos, en lo que toca a las tensiones que dan cuenta de la relación entre las categorías: jóvenes, cultura escolar-cultura social juvenil, comunicación y subjetividad, se puede sostener que existe un desencuentro entre cultura escolar y cultura social juvenil, una fractura científica entre saberes y experiencias y un divorcio entre la forma como educan la escuela y los medios de comunicación, factores que han generado ciertos quiebres en el proceso educativo, porque no se ha logrado comprender que la escuela tiene significado para los jóvenes cuando existe en ella un alcance cultural y un sentido, cuando el conocimiento escolar construye sus vidas, cuando les proporciona motivos para estar ahí en relación con otros escenarios -sus escenarios-, cuando las prácticas pedagógicas no los excluyen socialmente y cuando los reconocen como sujetos sociales.

Esta comprensión determina el aprendizaje y la configuración del sujeto juvenil en la escuela y está mediada por: 1) una relación imprescindible entre los espacios institucionales (familia, escuela y trabajo) y los tiempos no institucionalizados (barrio, calle y grupo de pares); 2) condiciones subjetivas relacionadas con los saberes, los sentidos y las experiencias desde las cuales se construye la formación de sujetos; y 3) la apertura a la relación entre el juego de subjetividades en el que se integren desarrollos cognitivos dirigidos por la escuela y desarrollos experienciales construidos dentro y fuera de esta.

Ahora bien, el estudio de estos antecedentes investigativos, además de dar pautas para la comprensión de la escisión entre discursos pedagógicos abstractos y teorías vigentes, provoca cierta preocupación, por la persistente separación entre teoría y práctica pedagógica, vacío epistémico que se ha encontrado en la relación de las prácticas pedagógicas con la educación en la escuela, en términos de cultura. A la luz de esta estimación -y con la idea de que desde el campo sociodiscursivo se aprecia que las investigaciones sobre los jóvenes en la cultura escolar vienen enfocando sus intereses más en los rasgos lingüísticos de la oralidad y la escritura que en el lenguaje visual-, se genera un interés particular por construir un saber práctico y pedagógico en una de las dimensiones que tensionan más fuertemente la educación hoy: el vínculo entre educación y cultura (Martín-Barbero, 2003, p. 12), concretamente en las dinámicas comunicativas que subyacen a la relación pedagógica -cultura de la imagen/configuración subjetiva de los jóvenes-, por ser hoy el lenguaje más persuasivo, atractivo y revelador.

Partiendo de la consideración de la imagen como elemento que condiciona la forma de ser, se propone pensarla hoy en los procesos de construcción del saber y del ser; es decir, tomar en serio el rol de la cultura visual, desde el punto de vista de la comunicación y la expresión. Así, es importante reflexionar sobre la forma como las imágenes en el mundo del conocimiento y del sentimiento permiten movilizarse a altas velocidades, ir de lo desconocido a lo conocido, crear relaciones y construcciones sociales entre mundos y contextos lejanos, opuestos y distintos, movilizar sujetos de forma masiva y simultánea, estar juntos, y dar forma a los seres 
humanos, especialmente a aquellos que están más condicionados por los valores culturales: "los jóvenes".

En esta dirección, la preocupación por romper con la lógica tradicional, según la cual el sujeto en la escuela está desligado de la cultura en que vive, se advierte la necesidad de fortalecer prácticas pedagógicas relacionadas con la cultura de la imagen, sin caer en una función instrumental de carácter educativo, sino entendiéndola como proceso comunicativo y acto sociocultural que le permite al joven escolar relacionarse en la cultura contemporánea con el conocimiento, construir representaciones de sí mismo y del otro, enseñar a mirar su mundo y otros mundos, juntar sus historias con otros saberes; es decir reconocerse a sí mismo y explorar sus posibilidades expresivas a través de experiencias satisfactorias y atractivas visualmente. Esta construcción dibuja un escenario que presenta un desafío para la educación, porque incita a superar el divorcio entre teoría y práctica y posibilita la construcción de prácticas pedagógicas alternativas a través del trabajo con la imagen. Lo que implica repensar la cultura escolar, sus formas de organizar los tiempos y los espacios y de clasificar a los alumnos y a los saberes (cfr. Tyack y Cuban, 1995).

\section{Agradecimientos}

A la doctora Sandra Soler, por su sabiduría, paciencia y entrega incondicional.

\section{Sobre la autora}

Flor Ángela Gutiérrez-Castro es licenciada en Artes Plásticas, Universidad de La Sabana. Magíster en docencia, Universidad de La Salle. Estudiante del doctorado interinstitucional en Educación, sede Universidad Distrital Francisco José de Caldas. Docente del Área de Educación Artística y de Cultura en escuela pública de Bogotá (Colombia).

\section{Referencias}

Abrantes, P. \& Da Costa, A. F. (2003). Os sentidos da escola: identidades juvenis e dinâmicas de ecolaridade. Oeiras: Celta.

Aguirre, I. (2013). Introducción. En Investigar con jóvenes: ¿Qué sabemos de los jóvenes como productores de cultura visual? Pamplona: Pamiela-Edarte (UPNA/NUP). Recuperado de http://edarte.org/wp-content/uploads/2013/03/Investigar_con_jóvenes_Edarte.pdf

Antelo, E. (2006). Mirando la escuela de noche. En Educar la mirada. Políticas y pedagogías de la imagen. Buenos Aires: Manantial, Flacso-OSDE.

Arfuch, L. (2006). La subjetividad en la era de la imagen: De la responsabilidad de la mirada. En Educar la mirada. Políticas y pedagogías de la imagen. Buenos Aires: Manantial, Flacso-OSDE.

Barker, G. (1950). Pachuco: An American-Spanish Argot and its Social Functions in Tucson, Arizona. University of Arizona Bulletin Series, $21,1$.

Berardi, F. (2007). Generación Post-Alfa. Patologías e imaginarios en el semiocapitalismo. Buenos Aires: Tinta Limón.

Bolívar, A. (2002). "¿De nobis ipsis silemus?": Epistemología de la investigación biográfico-narrativa en educación. Revista Electrónica de Investigación Educativa, 4 (1).

Cajiao, F. (1995). Proyecto Atlántida: adolescencia y escuela: una mirada desde la óptica de los adolescentes de educación secundaria en 
Colombia. Informe final. Bogotá: Fundación para la Educación Superior FES-Colciencias.

Cajiao, F. (1996). Atlántida: Una aproximación al adolescente escolar colombiano. Nómadas, 4, 53-65.

Cobo Romani, C. \& Moravec, J. W. (2011). Aprendizaje invisible. Hacia una nueva ecología de la educación. Barcelona: UNA. Colección Transmedia XXI.

Chervel, A (1988). L'histoire des disciplines scolaires. Réflexions sur un domaine de recherche. Histoire de l'Éducation, 38, 59-119 [trad. Historia de las disciplinas escolares. Reflexiones sobre un campo de investigación. Revista de Educación, 295 (1991), 59-111].

Dubet, F. \& Martuccelli, D. (1998). En la escuela. Sociología de la experiencia escolar. España: Losada.

Dussel, I. (2005). Educar la mirada: notas sobre los aportes de la mirada a la formación docente. Revista Belo Horizonte, V (41), 157-174.

Dussel, I. y Gutiérrez, D. (comps.) (2006). Educar la mirada: políticas y pedagogías de la imagen. Buenos Aires: Manantial, Flacso-OSDE.

Duschatzky, S. (2006). Perplejidades incesantes, subjetividades de intemperie. En Educar la mirada. Políticas y pedagogías de la imagen. Buenos Aires: Manantial, Flacso-OSDE.

Edarte, Grupo de Investigación (ed.) (2009). Jóvenes productores de cultura visual: competencias y saberes artísticos en educación secundaria. Pamplona: Pamiela-Edarte (UPNA/NUP). Recuperado de http://edarte.org/jovenesproductorescv

Edarte, Grupo de Investigación (ed.) (2013). Investigar con jóvenes: ¿Qué sabemos de los jóvenes como productores de cultura visual? Pamplona: Pamiela-Edarte (UPNA/NUP). Recuperado de http://edarte.org/wp-content/uploads/2013/03/ Investigar_con_jóvenes_Edarte.pdf

Feixa, C. (2010). Escuela y cultura juvenil. ¿Matrimonio mal avenido o pareja de hecho? Revista Educación y Ciudad, 18. Instituto para la Investigación Educativa y el Desarrollo Pedagógico (IDEP), Bogotá.

Fischman, G. (2006). Aprendiendo a sonreír, aprendiendo a ser normal. Reflexiones acerca del uso de fotos escolares como analizadoras en la investigación educativa. En Educar la mirada. Políticas y pedagogías de la imagen. Buenos Aires: Manantial, Flacso-OSDE.

Forquin, J.-C. (1989). École et culture: le point de vue des sociologues britanniques. Bruxelles: De Boeck-Wesmael.

Foucault, M. (1976). Vigilar y castigar. Nacimiento de la prisión. Barcelona: Siglo XXI.

Foucault, M. (1990). La vida de los hombres infames. Ensayos sobre desviación y dominación: Argentina: Altamira.
Foucault, M. (1991). El sujeto y el poder. Bogotá: Carpe Diem.

Foucault, M. (2005). Nacimiento de la biopolítica. México: Fondo de Cultura Económica.

Gutiérrez, A. B. (2007a). Cultura escolar y subjetividad: a propósito de los jóvenes en nuestro país. JOVENes. Revista de Estudios sobre Juventud, 27, 146161. Instituto Mexicano de la juventud.

Gutiérrez, A. B. (2007b). Miradas sociopsico-pedagógicas en torno a los jóvenes: notas iniciales. JOVEnes. Revista de Estudios sobre Juventud, 26, 67-80. Instituto Mexicano de la juventud.

Hernández, F. (2011). Investigar con los jóvenes: cuestiones temáticas, metodológicas, éticas y educativas. En línea: http://diposit.ub.edu/dspace/ bitstream/2445/17362/6/Investigar $\% 20$ con $\% 20$ los\%20j\%C3\%B3venes.pdf

Hernández, F. (2013). Transitar y aprender dentro y fuera de la escuela: la relación de los jóvenes con la cultura visual como espacio de posibilidad y autoría. En Investigar con jóvenes. ¿Qué sabemos de los jóvenes como productores de cultura visual? Pamplona: Pamiela-Edarte (UPNA/NUP). Recuperado de http://edarte.org/wp-content/ uploads/2013/03/Investigar_con_jóvenes_Edarte.pdf

Herrero, G. (2002). Aspectos sintácticos del lenguaje juvenil. En El lenguaje de los jóvenes. Barcelona: Ariel.

Huergo, J. (2000). Comunicación/Educación. Itinerarios transversales. En Comunicación-Educación, coordenadas, abordajes y travesías (pp. 3-25). Bogotá: Universidad Central- DIUC, Siglo del Hombre. Serie Encuentros.

Huergo, J. (2006). Una guía de comunicación/educación, por las diagonales de la cultura y la política. Nodos de Comunicación/Educación, 5. Revista Virtual, Centro de Comunicación y Educación.

James, A., Jenks, Ch. \& Prout, A. (2008). Teorizing childhood. Teachers College Press, Teachers College, Columbia University.

Kaplún, M. (1998). Una pedagogía de la comunicación. Madrid: La Torre.

Levinson Bradley, A. U. (2012). Reduciendo brechas entre cultura juvenil y cultura escolar docente en América Latina: el desafío institucional para crear una secundaria con sentido. En La escolarización de los adolescentes: Desafíos culturales, pedagógicos y de política educativa. Buenos Aires: Instituto Internacional de Planeamiento de la Educación (IIPE), Unesco.

López, U. (2013). Los nuevos Guernicas. Reflexiones en torno al trabajo con jóvenes productores de cultura visual. En Investigar con jóvenes: ¿Qué sabemos de los jóvenes como productores de cultura 
visual? Pamplona: Pamiela-Edarte (UPNA/NUP). Recuperado de http://edarte.org/wp-content/ uploads/2013/03/Investigar_con_jóvenes_Edarte.pdf

Malosetti Costa, L. (2006). Algunas reflexiones sobre el lugar de las imágenes en el ámbito escolar. En Educar la mirada. Políticas y pedagogías de la imagen. Buenos Aires: Manantial, Flacso-OSDE.

Martín-Barbero, J. (2003). De los medios a las mediaciones. Comunicación, cultura y hegemonía. Bogotá: Convenio Andrés Bello.

Mead, M. (1977). Cultura y compromiso. El mensaje a la nueva generación. Barcelona: Granica.

Merino Malillos, L. (2010). Nativos digitales: Una aproximación tecnológica de los jóvenes. Universidad del País Vasco.

Milstein, D., Clemente, A., Dantas-Whitney, M., Guerrero, A. L. \& Higgins, M. (2011). Niños, niñas y adolescentes: sujetos de etnografías. Revista Mexicana de Investigación Educativa, 17 (55).

Morant, R. (2002). El lenguaje de los estudiantes: Un paseo por las aulas. En El lenguaje de los jóvenes. Barcelona: Ariel.

Montenegro González, C. (2013). Novelas gráficas: reconstrucciones de la memoria. En Investigar con Jóvenes: ¿Qué sabemos de los jóvenes como productores de cultura visual? Pamplona: Pamiela-Edarte (UPNA/NUP). Recuperado de http:// edarte.org/wp-content/uploads/2013/03/Investigar_con_jóvenes_Edarte.pdf

Muñoz González, G. (2007). La comunicación en los mundos de vida juveniles. Hacia una ciudadanía comunicativa. Universidad de Manizales. Cinde.

Muñoz González, G. (2009). Las culturas juveniles: mutaciones en el cambio de la época. Revista Educación y Ciudad, 18. IDEP, Bogotá.

Muñoz González, G. \& Muñoz, D. (2008). La ciudadanía juvenil como ciudadanía cultural: Una aproximación teórica sobre los estudios culturales. Revista Argentina de Sociología, 11, 217-236.

Pancani, D. (2006). Juicios y prejuicios sobre el soporte audiovisual. La mirada de los actores educativos en Chile. En Educar la mirada. Políticas y pedagogías de la imagen. Buenos Aires: Manantial, Flacso-OSDE.

Parra-Sandoval, R. (1996). El tiempo mestizo: escuela y modernidad en Colombia. En Escuela y modernidad en Colombia. T. I, Alumnos y maestros (pp. 227-258). Bogotá: Fundación para la Educación Superior (FES), Instituto para la Investigación Educativa y el Desarrollo Pedagógico (IDEP), Fundación Restrepo-Barco.
Pereira Leão, G. M. (2012). Rumbos de la vida, sentidos de la escuela: diálogos juveniles sobre la educación secundaria. En La escolarización de los adolescentes: Desafíos culturales, pedagógicos y de política educativa. Buenos Aires: Instituto Internacional de Planeamiento de la educación (IIPE), Unesco.

Reguillo Cruz, R. (2006). Políticas de la mirada. Hacia una antropología de las pasiones contemporáneas. En Educar la mirada. Políticas y pedagogías de la imagen. Buenos Aires: Manantial, Flacso-OSDE.

Reyes Juárez, A. (2010). Más allá de los muros: adolescencias rurales y experiencias estudiantiles en telesecundarias. México: Flacso. Recuperado de http://hdl.handle.net/10469/1799

Richard, N. (2006). Estudios visuales y políticas de la mirada. En Educar la mirada. Políticas y pedagogías de la imagen. Buenos Aires: Manantial, Flacso-OSDE.

Rockwell, E. (2010). Nuestros pasos por la escuela. Lo que queda y lo que cambia. México: SM.

Rodríguez, F. (2002). El lenguaje de los jóvenes. BarceIona: Ariel.

Rodríguez Lestegás, F. (2006). Cultura escolar, ideología y geografía: de la "identidad nacional" a la "identidad europea", o la construcción de un nuevo objeto de enseñanza. Revista de Educación, 339, 837-858.

Serra, M. S. (2006). Juicios y prejuicios sobre el soporte audiovisual. La mirada de los actores educativos en Chile. En Educar la mirada. Políticas y pedagogías de la imagen. Buenos Aires: Manantial, Flacso-OSDE.

Tenti Fanfani, E. (2000). Culturas juveniles y cultura escolar. Seminario Escola Jovem: un novo olhar sobre o ensino médio. Ministerio da Educaçao, Secretaria de Educaçao Média e Tecnológica. CoordenaçaoGeral de Ensino Médio (Brasilia). Trabajo autorizado por el IIPE/Unesco, Buenos Aires.

Tyack, D. \& Cuban, L. (1995) Por qué persiste la gramática de la escolaridad. En En busca de la utopía. Un siglo de reformas de las escuelas públicas. México: Fondo de Cultura Económica.

Tiramonti, G. (2012). Dimensiones en la discusión de la problemática de la escuela media. En La escolarización de los adolescentes: Desafíos culturales, pedagógicos y de política educativa. Buenos Aires: Instituto Internacional de Planeamiento de la educación (IIPE), Unesco.

Zimmermann, K. (2002). La variedad juvenil y la interacción verbal entre jóvenes. En El lenguaje de los jóvenes. Barcelona: Ariel. 